\title{
Growth and Carotenoid Contents of Intercropped Vegetables in Building-Integrated Urban Agriculture
}

\author{
Jin-Hee Ju, ${ }^{1}$ Sun-Young Cho, ${ }^{2}$ Hee-Yeon Song, ${ }^{1}$ Seyoung Ju, ${ }^{2}$ Yong-Han Yoon, ${ }^{1}$ \\ and Kyung-Jin Yeum $\mathbb{D}^{2,3}$ \\ ${ }^{1}$ Department of Green Convergence Technology, College of Science and Technology, Konkuk University, \\ Chungju-si, Republic of Korea \\ ${ }^{2}$ Department of Integrated Biosciences, College of Biomedical Science, Konkuk University, Chungju-si, Republic of Korea \\ ${ }^{3}$ Research Institute for Biomedical \& Health Science, Konkuk University, Chungju-si, Republic of Korea
}

Correspondence should be addressed to Kyung-Jin Yeum; kyeum@kku.ac.kr

Received 5 July 2021; Revised 15 September 2021; Accepted 23 September 2021; Published 13 October 2021

Academic Editor: Aqeel Ahmad

Copyright (c) 2021 Jin-Hee Ju et al. This is an open access article distributed under the Creative Commons Attribution License, which permits unrestricted use, distribution, and reproduction in any medium, provided the original work is properly cited.

\begin{abstract}
Sustainable food security due to climate and social change is more important than ever. This study was conducted to increase plant growth and bioactive contents using intercropping technology in urban agriculture. Tomatoes (Solanum lycopersicum L.) and sunflowers (Helianthus annuus L.) were intercropped in different ratios in outdoor rooftop, and lettuce (Lactuca savita L.) was grown with chicory (Cichorium intybus. L.) in the indoor LED plant growth chambers. Carotenoids in plant foods were analyzed using an ultraperformance liquid chromatography with photodiode array detection. Chlorophyll contents were determined by the soil analysis development chlorophyll meter. Tomatoes planted with sunflowers $(3: 1)$ had a significantly larger stem diameter $(p<0.05)$, a large number of leaves $(p<0.05)$, and significantly higher lycopene at $\mathrm{d} 88(p<0.05), \mathrm{d} 102(p<0.001)$, and $\mathrm{d} 115$ $(p<0.01)$, and $\beta$-carotene contents at $\mathrm{d} 102(p<0.05)$ as compared to those of monocultured tomatoes. Lettuce planted in a ratio of $1: 3$ with lettuce and chicory had significantly higher contents of chlorophyll $(p<0.05)$, $\beta$-carotene $(p<0.05)$, and lutein $(p<0.01)$, than lettuce planted alone. On the other hand, intercropping of chicory and lettuce did not have a beneficial effect on the growth and carotenoid content of chicory. The current study indicates that plant growth and carotenoid content can be substantially modified by cocultivation, and the effects may vary depending on the type of plant and the crop ratio.
\end{abstract}

\section{Introduction}

Urban agriculture, a food production system of inside city boundaries or densely populated areas, has become an attractive land use alternative in modern society [1]. Urban agriculture's social, economic, and environmental contributions are becoming more important than ever [2]. In particular, there is a new interest in urban agriculture as a means of securing food supply in the context of climate change and other impacts such as the COVID-19 pandemic in all parts of the world [3]. Rooftop gardens, providing an alternative controlled space for growing vegetables, have recently become an important part of urban agriculture revitalization [4, 5]. In addition, indoor farm that can produce plants year-round with controlled lighting is rapidly expanding in urban and suburban areas $[6,7]$. Along with such building-integrated urban agriculture, interest in improving the nutritional and bioactive content of crops is increasing [8-10].

In recent years, growing mix crops has become an important component of sustainable organic farming [11]. Cocultivation is a cross-crop practice often associated with organic farming and can increase in productivity of vegetables per unit area [12]. Growing two or more plants together is usually a method of disease management for crops. However, it can positively change the microclimate conditions around the canopy as well as add organic matter and nitrogen to the soil to retain water and nutrients and control weeds [13]. Additionally, adding noncrop vegetation to a single cultivation helps preserve biodiversity through 
resource diversification and reduced use of pesticides [14]. Although these practices can be beneficial to agriculture, they are not practically utilized [15]. Therefore, it is important to demonstrate beneficial effects of easy-to-implement companion planting for urban agricultural farmers and consumers.

Tomato species are a key component of nutrition in many countries and are of great economic importance worldwide [16, 17]. However, continuous single cropping and excessive fertilizer application of tomato plants led to soil acidification and salinization in many areas, reducing tomato yield and fruit quality [18-20]. It has been reported that the yields of tomatoes can be increased when grown with tall sunflower in regions with high light intensities [21]. However, the effect on the bioactive contents in tomatoes grown with sunflowers has not yet been reported.

Lettuce can be a good potential source of bioactive substances such as carotenoids [22], and as Hernandez et al. recently reported [23], their contents can be modified through fertilization management. In addition, LEDs have been reported to improve plant performance and carotenoid content in lettuce [24] and help overcome unpredictable weather conditions [25].

Therefore, we investigated the effects of cocultivation on plant growth and bioactive components by utilizing the outdoor rooftop garden of tomatoes with sunflowers and indoor LED growth chamber of lettuce and chicory in urban agriculture with limited farmland.

\section{Materials and Methods}

An outdoor roof garden and indoor LED plant growth chamber were utilized to produce plant foods mimicking urban agriculture. Tomatoes (Solanum lycopersicum L.) and sunflowers (Helianthus annuus L.) were intercropped in different proportions in the roof garden, and lettuce (Lactuca savita L.) was grown with chicory (Cichorium intybus. L.) in different ratios in LED plant growth chamber as summarized in Figure 1.

The overall conditions of outdoor rooftop gardens and indoor LED growth chamber are presented in Table 1.

2.1. Outdoor Experimental Design: Rooftop Garden. The outdoor experiments were carried out on the rooftop garden of a complex practice building at the university campus $\left(35^{\circ} 49^{\prime} \mathrm{N}, 127^{\circ} 08 \mathrm{~N}\right)$, Chungju-si, South Korea. There were a total of 15 square plots $(100 \mathrm{~cm}$ length $\times 100 \mathrm{~cm}$ width $\times 30 \mathrm{~cm}$ height) which were made of brick and mortar constructed in full sun at the field experiment rooftop. This plot consists of three layers (from bottom to top): a drainage layer, filter fabric, and growing substrate. The drainage layer had a $25 \mathrm{~mm}$ thick drainage board with a high impact polystyrene dimple sheet. A nonwoven geotextile fabric was bonded to the upper surface of the drainage board as the filter layer, which prevented the small particles from being washed from the substrate layer. The growing substrate was filled with a $25 \mathrm{~cm}$ depth of commercial substrate (Hansel Green Co., Ltd., Korea) for green roofs
Tomato (Solanum lycopersicum L.) and sunflower seedlings (Helianthus annuus L.) were obtained from a nursery under natural conditions nearby and transplanted together in the rooftop plots with a plant density of 12 plants per square meter. Experimental treatments were the fourcompanion planting at different tomato to sunflower ratios as follows: tomato control ( $\mathrm{T}$ alone, tomato monoculture); tomato: sunflower $=1: 1 \quad(\mathrm{~T} 1 \mathrm{~S} 1) ; 2: 1 \quad$ (T2S1); and $3: 1$ (T3S1). The outdoor experiments on the rooftop garden were conducted using a randomized complete plot design with four treatments and three replications (a total 12 plots) as shown in Figure 2. During the experiments, regular cultural practices were applied as needed, uniformly through all experimental plots, without any additional fertilization during the growing seasons.

Plant height, diameter of the stem, number of leaves, and leaf shape index were recorded for each treatment when plants were at their peak growth time. These parameters have been used to reflect plant growth rates, competitive ability, and resource use [26]. Plant height $(\mathrm{cm})$ was measured with a meter measuring tape at the vertical distance between the upper boundary of the plant and ground level. Stem diameter was determined using Vernier digital calipers (500-153, Mitutoyo Co., Japan) at the plant base.

Tomato fruits were collected three times while fully ripened (early harvest ( 88 days), midharvest (102 days) and late harvest (115 days)). An average of 30 fully ripe tomatoes from each experimental plot were harvested at each time point and were randomly transferred to the laboratory in plastic bags (Ziploc, Johnson \& Son, USA) within $1 \mathrm{~h}$ of harvest for carotenoid analysis.

\subsection{Indoor Experimental Design: LED Plant Growth} Chamber. The indoor experiment was set up in the laboratory using a randomized miniplastic container with nine replicates. Experimental treatments were seven different seed mixture ratios of lettuce seeds (Lactuca savita L., Jeilseed Bio Co., Ltd., Korea) and chicory seeds (Cichorium intybus. L., Asia Seed Co., Ltd., Koera) as follows: 40 lettuce seeds (L alone), 20 lettuce seeds +20 chicory seeds (L1C1), 13 lettuce seeds +27 chicory seeds (L1C2), 10 lettuce seeds +30 chicory seeds (L1C3), 27 lettuce seeds +13 chicory seeds (L2C1), 30 lettuce seeds +10 chicory seeds (L3C1), and 40 chicory seeds ( $\mathrm{C}$ alone). Companion sowing experiments were conducted in nine replicates for each of the seven seed mixture ratios (a total of 63 miniplastic containers).

Seeds of the seven different mixtures were sown in each miniplastic container $(20 \mathrm{oz})$ containing $15 \mathrm{~g}$ perlite (New PerlShine No. 3, Green Fire Chemicals Co., Ltd., Korea) and $65 \mathrm{~g}$ of commercial horticultural substrates (Hanpanseung, Samhwa Greenwell Co., Ltd., Korea) from bottom to top. After sowing, miniplastic containers were irrigated with mist water $(100 \mathrm{ml})$, and a thin layer of horticultural substrates is placed over the seed $(\sim 5 \mathrm{~mm})$ with each container covered with a plastic cap to maintain moisture content. Seedlings were grown in environmentally controlled LED plant growth chambers (Masuda Co., Ltd., Korea), where three cultivation frames with $150 \mathrm{~cm} \times 70 \mathrm{~cm} \times 35 \mathrm{~cm}$ 


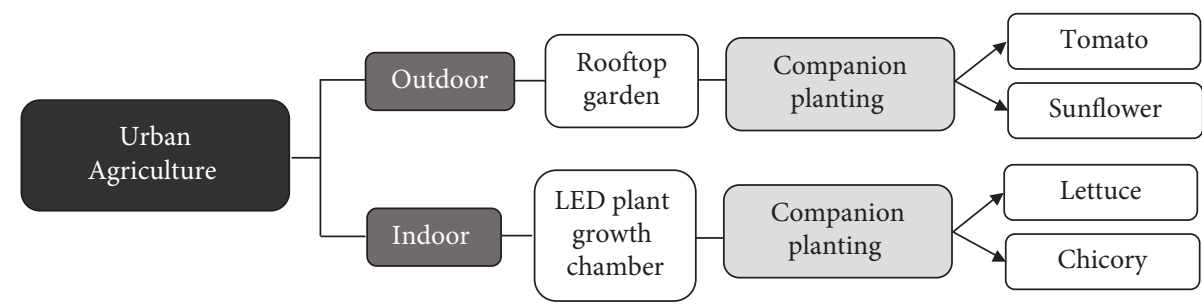

FIGURE 1: Flowchart of the study.

TABLE 1: Growth conditions for companion planting of urban agriculture.

\begin{tabular}{lcc}
\hline & \multicolumn{2}{c}{ Urban agriculture } \\
Condition & Rooftop garden (tomato and sunflower) & LED plant growth chamber (green lettuce and chicory) \\
\hline Temperature & $23.8^{\circ} \mathrm{C}(11.2 \sim 32.1)^{z}$ & $27.7^{\circ} \mathrm{C}(24.7 \sim 31.6)$ \\
Humidity & $66.6 \%(45.3 \sim 93.1)$ & $37.3 \%(25.6 \sim 53.6)$ \\
Illuminance & & 10000 lux \\
\hline
\end{tabular}

${ }^{z}$ Mean (minimum maximum).

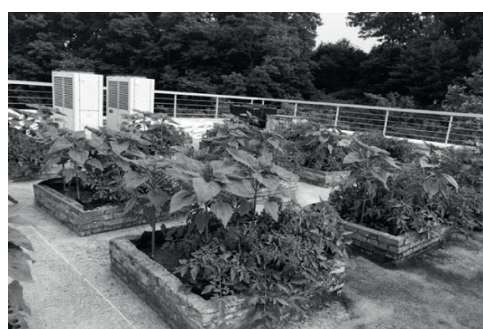

(a)

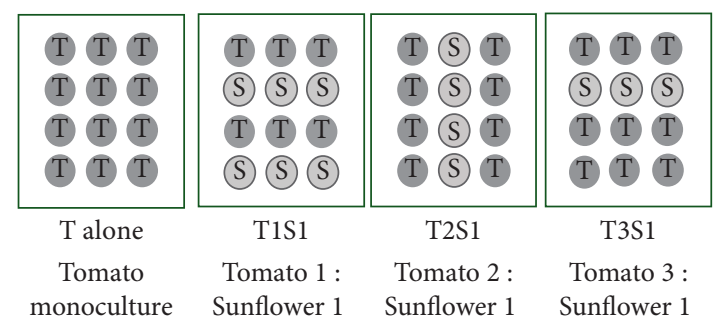

(b)

Figure 2: The outdoor experimental site (a) and schematic illustration (b) of the companion planting ratios between tomatoes and sunflowers in the plots on the rooftop garden.

(length $\times$ width $\times$ height) were installed providing the same light treatment as shown in Figure 3.

In the growth chamber, $\mathrm{CO}_{2}$ concentration was the same as the ambient atmosphere, light intensity was 10,000 lux, the photoperiod was $16 \mathrm{~h}$ continuing from $06: 00$ to $22: 00$, day/night temperature was $25 / 21^{\circ} \mathrm{C}$, and relative humidity was $\sim 65 \%$. The number of leaves, leaf shape index, chlorophyll contents, and fresh weights were evaluated for nine plants per treatment at day 23 immediately after sowing. The leaf shape index of the third leaf from the basal part was calculated by dividing leaf length by leaf width. Chlorophyll contents were determined by the soil analysis development chlorophyll meter (SPAD-502, Konica Minolta Co., Japan). It was measured in the middle of leaf per each treatment. The fresh weights of shoots and roots were measured using a digital scale (IP65, A\&D Co., Japan). At 25 days after sowing (baby leaf stage), lettuce samples were collected in $\sim 60 \mathrm{ml}$ sample bags (LDPE, Cleanwrap Co., Ltd., Korea), wrapped in aluminum foil and immediately transported to the laboratory within $1 \mathrm{~h}$ of harvest for carotenoid analysis.

2.3. Carotenoid Analysis. The uniform, nonsenescent, and undamaged edible portion of plant samples were washed with $\mathrm{d}-\mathrm{H}_{2} \mathrm{O}$, dewatered, and minced immediately after transport to the laboratory. Samples were extracted for carotenoids and aliquoted $1 \mathrm{~g}$ each in a freezer vial and stored at $-80^{\circ} \mathrm{C}$ for further analysis. All procedures were conducted under red light.

One gram each of plant samples were placed in $50 \mathrm{~mL}$ glass vials, and $5 \mathrm{~mL}$ of methanol was added and vortexed for $30 \mathrm{sec}$. Plant samples and methanol mixtures were incubated for $1 \mathrm{hr}$ at room temperature. Afterwards, the mixture was homogenized for $30 \mathrm{~s}$ in an ice bath. The mixture was centrifuged at $3000 \mathrm{rpm}$ for $5 \mathrm{~min}$. The methanol layer was transferred into a $50 \mathrm{~mL}$ volumetric flask, and the extraction was repeated four times with $10 \mathrm{~mL}$ of tetrahydrofuran (THF), followed by vortex and centrifugation. The THF layers were combined with the methanol layer and the volume was brought up to $50 \mathrm{~mL}$. One $\mathrm{mL}$ of the extract was taken, dried under nitrogen, and resuspended in $100 \mu \mathrm{L}$ of ethanol. All extraction procedures for carotenoid analysis were carried out under red light.

Carotenoids were analyzed using a previously reported UPLC-Photodiode Array Detector analysis [27] with minor modification. In brief, the UPLC (ACQUITY UPLC I-Class, Waters Co., Milford, MA, USA) system was equipped with a BEH C18 column $(1.7 \mu \mathrm{m}, 2.1 \times 50 \mathrm{~mm}$, Waters Co., Milford, MA, USA), binary pump delivery system, autosampler, and photodiode array detector. Mobile phase A was acetonitrile/ methanol $(7: 3 . \mathrm{v} / \mathrm{v})$, and mobile phase B was water. Each sample was injected into the BEH C18 column $(1.7 \mu \mathrm{m}$, $2.1 \times 50 \mathrm{~mm}$ ). The gradient condition was similar to that previously reported [27]. 


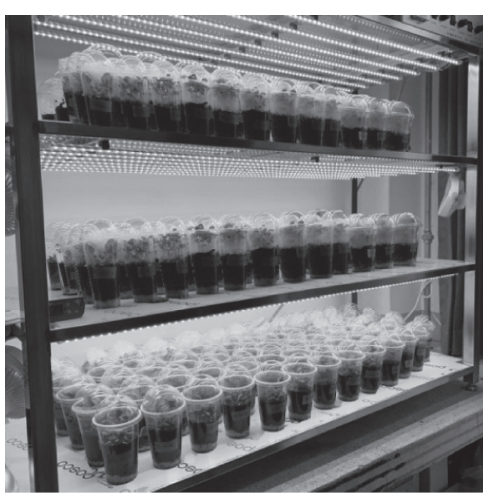

(a)

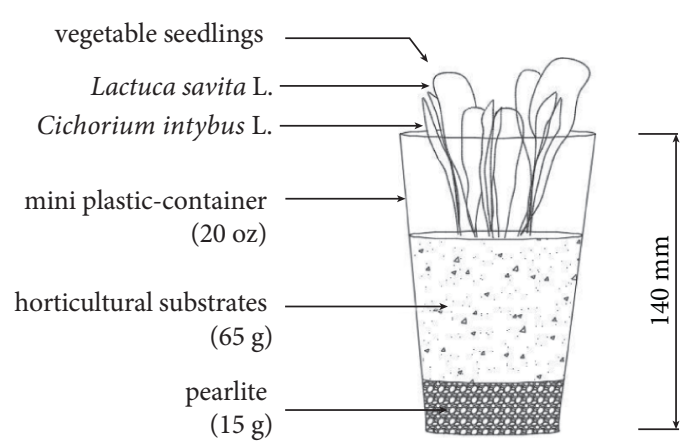

(b)

FIGURE 3: The indoor LED plant growth chamber experiments (a) and the cross section of miniplastic container (b) with different ratios of seed mixtures between lettuce and chicory.

$\beta$-Carotene, lutein, and lycopene (at $450 \mathrm{~nm}$ ) were quantified by each standard curve. Each peak was confirmed by retention time and its unique spectrum. The interassay coefficient of variation $(\mathrm{CV})$ was under $4 \%(n=10)$, and the intra-assay CV was under $4 \%$ as well $(n=10)$.

Representative UPLC profiles of carotenoids from tomato, lettuce, and chicory, and spectra of corresponding carotenoids are shown in Figure 4.

2.4. Statistical Analysis. The experiment was designed as a completely randomized design to test the effect of companion plantings or sowings ratios on all measured parameters. One-way analysis of variance was conducted, and a mean comparison among treatments was conducted using Duncan's multiple range tests $(p<0.05)$. All statistical analyses were performed using SPSS statistical software version 18.0 (SPSS Inc., Chicago, USA).

\section{Results and Discussion}

The current study reports the companion planting, which was originally used for disease management $[28,29]$ and improving plant productivity [30], which can be utilized to improve plant growth and bioactive contents in buildingintegrated urban agriculture. We believe that increasing the availability of a nutritious food supplies through buildingintegrated urban agriculture can be a useful strategy to overcome food and nutrient instability caused by climate and environmental changes in modern society [31].

\subsection{Growth and Carotenoid Contents in Intercropped To-} matoes with Sunflower. In the current study, there was no significant difference in the leaf shape index of tomatoes regardless of the cocultivation rate of tomato and sunflower. However, tomatoes grown in a ratio of 3 to 1 with tomatoes and sunflowers had significantly higher $(p<0.05)$ plant heights, stem diameters, and leaf counts compared to tomatoes grown alone (Table 2).

Considering the height of the sunflower plant was not less than $1.5 \mathrm{~m}$ and above the tomato stands $0.5 \mathrm{~m}$, the tomato plant was protected from direct solar radiation by shady cool air columns. In addition, shading tomato plants creates an ambient microenvironment with high relative humidity, which clearly mitigates moisture loss in tomato plants [32]. On the other hand, the stem diameter and leaf count of tomatoes decreased as the percentage of sunflower cocultivation increased, indicating interspecies competition for sunlight. This suggests that although cocultivation of tomatoes and sunflowers may provide benefits against heat stress as previously reported [33], the increased number of sunflowers may provide tomatoes excessive shading, which can adversely affect their growth parameters.

A green roof with a variety of vegetation structures and colors is a system favored by the public [34]. In the current study, tomatoes and sunflowers were grown together using an outdoor rooftop garden, given that tomatoes are a major component of nutrition in many countries and of economic importance worldwide [35]. White mustard [35] and marigold [28] have also been reported as promising companion crops for tomatoes.

When tomatoes were planted with sunflowers, carotenoid contents in tomatoes were significantly different as compared to those of tomatoes planted alone as shown in Figure 5. Lycopene contents of fully ripened first harvest tomatoes were $5.5 \mathrm{mg}$ and $6.0 \mathrm{mg} / 100 \mathrm{~g}$ FW Edible portion in monoculture and intercropping with lettuce and sunflower, respectively. This lycopene content is similar to the recently reported lycopene contents in cherry tomatoes that abscisic acid, a plant hormone, promoted lycopene accumulation from an undetectable level in green cherry tomatoes to $8 \mathrm{mg}$ per $100 \mathrm{~g} \mathrm{FW}$ of ripe tomatoes [36]. Companion cultivation of tomatoes with sunflowers at a 3 to 1 ratio yielded 9.6\%,26.9\%, and 5.4\% higher lycopene contents on days 88,102 , and 115 , respectively, than monocultured tomatoes. In addition, the $\beta$-carotene content was significantly higher in tomatoes planted in a 3:1 (tomato:sunflower) ratio with sunflowers at 102 days compared to tomatoes grown alone. However, the increase in $\beta$-carotene contents by companion planting was not as pronounced as the effect of harvest time. Lutein content was significantly higher in the $1: 1$ and 3:1 (tomato: sunflower) ratios compared to tomatoes grown alone. On the other hand, 

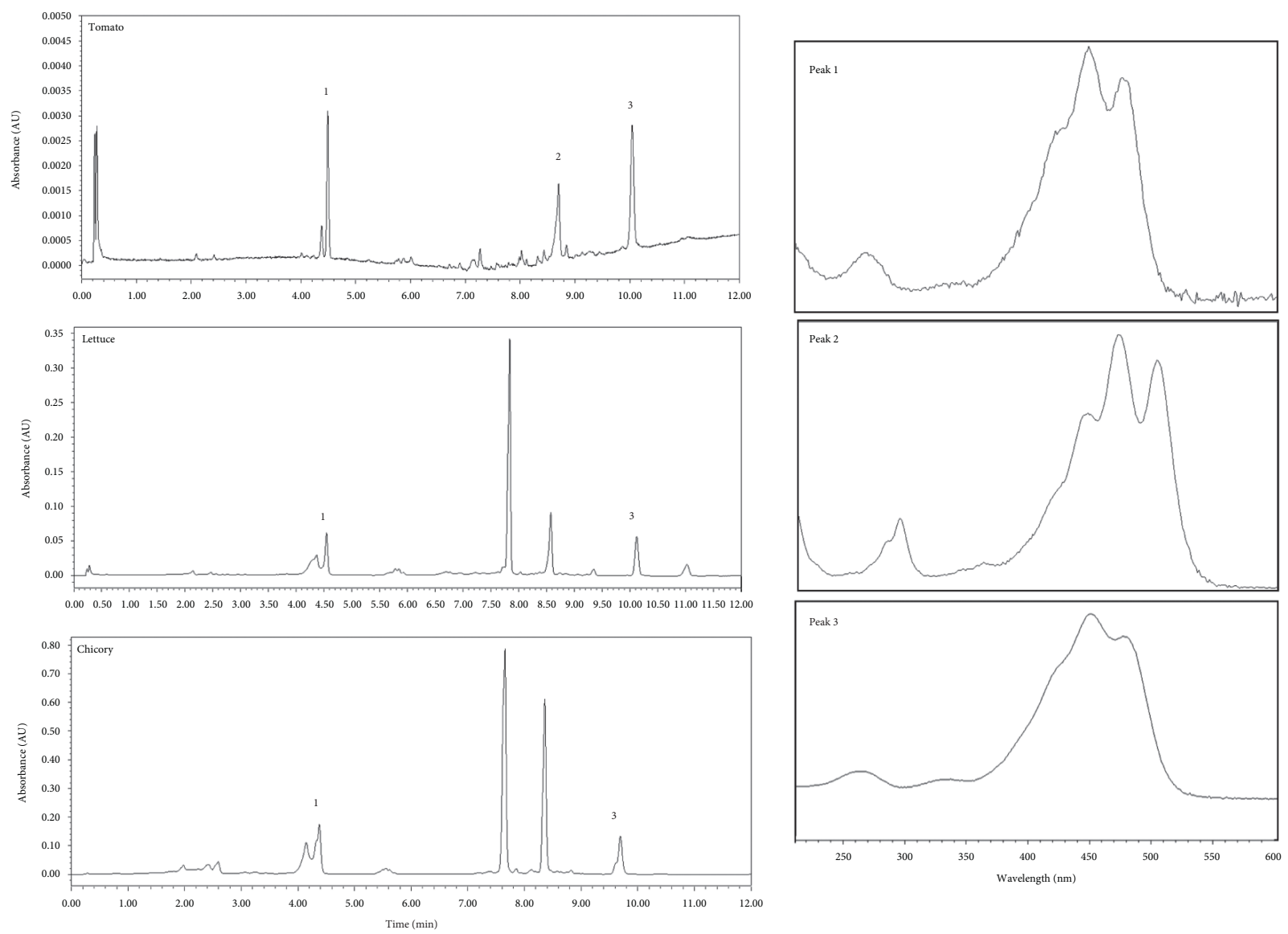

FIGURE 4: Representative UPLC profiles of carotenoids from tomato, lettuce, and chicory, and spectra of corresponding carotenoids.

TABLE 2: Plant growth parameters of tomatoes (Solanum lycopersicum) according to companion planting ratio with sunflower (Helianthus annuus) in green roofs at 88 days after planting.

\begin{tabular}{lcccc}
\hline Treatments & Plant height $(\mathrm{cm})$ & Stem diameter $(\mathrm{cm})$ & Number of leaves & Leaf shape index \\
\hline T alone & $80.33 \pm 0.90 \mathrm{c}$ & $17.71 \pm 0.38 \mathrm{bc}$ & $418.78 \pm 9.06 \mathrm{~b}$ & $1.76 \pm 0.03 \mathrm{a}$ \\
T1S1 & $105.55 \pm 0.83 \mathrm{a}$ & $14.75 \pm 0.17 \mathrm{c}$ & $326.44 \pm 2.31 \mathrm{c}$ & $1.68 \pm 0.02 \mathrm{a}$ \\
T2S1 & $86.44 \pm 0.68 \mathrm{bc}$ & $20.67 \pm 0.14 \mathrm{ab}$ & $320.89 \pm 3.35 \mathrm{c}$ & $1.57 \pm 0.02 \mathrm{a}$ \\
T3S1 & $92.89 \pm 0.95 \mathrm{~b}$ & $23.50 \pm 0.71 \mathrm{a}$ & $673.33 \pm 5.74 \mathrm{a}$ & $1.68 \pm 0.02 \mathrm{a}$ \\
\hline
\end{tabular}

T alone, tomatoes; T1S1, tomatoes : sunflower $=1: 1$; T2S1, tomatoes $:$ sunflower $=2: 1$; T3S1, tomatoes : sunflower $=3: 1$. Data are means \pm SE. The same letters are not significantly different within the same column according to Duncan's multiple range test at $p<0.05(n=9)$. Leaf shape index is leaf length/leaf width.

tomatoes grown by companion planting at a $2: 1$ (tomato: sunflower) ratio had significantly lower lutein and $\alpha$-carotene contents than tomatoes grown alone.

The current study indicates that the carotenoid contents in plant foods can be affected by the intercropping system as well as harvest time. It is interesting to note that the lycopene contents in tomatoes gradually reduced by harvesting time, and $\beta$-carotene content increased instead. Considering that the $\beta$-carotene contents are ranging from $2.51 \mathrm{mg}$ to $4.77 \mathrm{mg}$ / $100 \mathrm{~g}$ depending on the harvesting time, and that one cup of tomatoes $(200 \mathrm{~g})$ is one serving, one can theoretically obtain $418-795 \mu \mathrm{g}$ of retinol by consuming one serving of tomatoes. These results suggest that the harvest time of tomatoes can not only be determined based on the needs of specific carotenoids, but can also be optimized, and that tomatoes can provide significant amounts of carotenoids.
It is well known that lipophilic plant pigments such as carotenoids provide valuable nutritional and health benefits [37]. In addition to provitamin A activity of $\beta$-carotene [38], nonprovitamin A carotenoids such as lycopene lower the risk of oxidative stress-associated chronic diseases [39] and lutein has beneficial effects on eye health [40]. Therefore, we believe the results of this study can be the first step in establishing a strategy to achieve food and nutritional security through urban agriculture using intercrop strategies.

\subsection{Growth and Carotenoid Contents in Lettuce Intercropped} with Chicory. In the LED plant chamber, when lettuce was grown alone or with chicory, there was no significant difference in the number of leaves and fresh weight. However, the leaf shape index of lettuce was significantly lower when 

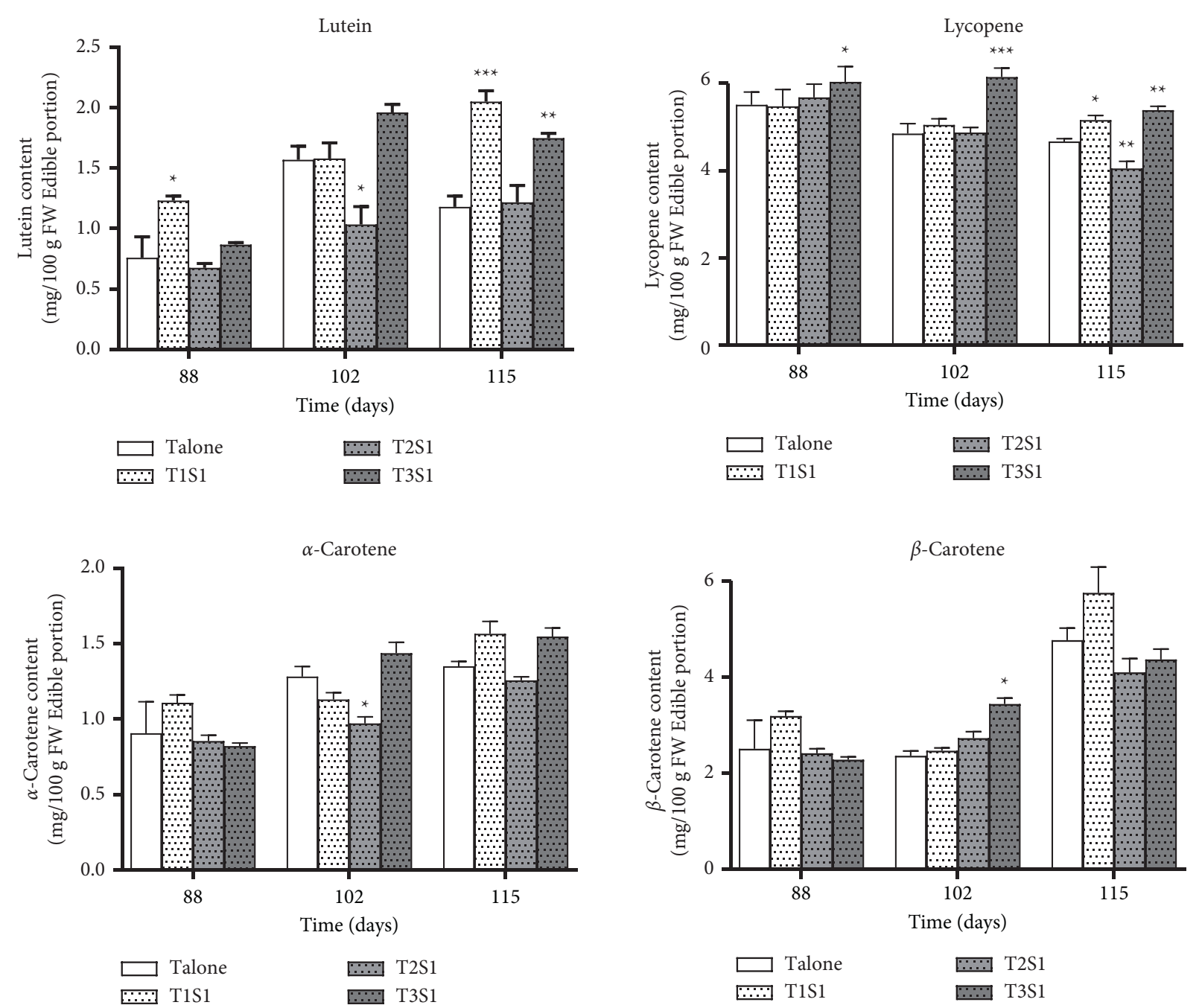

FIGURE 5: Effect of companion planting with sunflowers on carotenoid contents in tomatoes over time grown on the rooftop garden. Carotenoids were analyzed using an UPLC system (means \pm SE, $n=3$ ). Significantly different with the monoculture ${ }^{*} p<0.05,{ }^{* *} p<0.01$, and ${ }^{* * *} p<0.001$.

lettuce was cultivated with chicory at a ratio of $1: 3$ than lettuce grown alone $(p<0.05)$. In addition, the chlorophyll content of lettuce was also significantly $(p<0.05)$ higher in lettuce intercropped with chicory at a ratio of 1 to 3 (Table 3 ).

It is probable that the companion planting of lettuce and chicory can be beneficial for the strong growth of lettuce as reported earlier [41]. The competition between lettuce and chicory may generate stress conditions, which may lead to the synthesis of secondary metabolites since the general response to (a) biotic stress can be an increase in the synthesis of compounds [42]. On the other hand, chicory intercropped with lettuce had significantly lower leaf shape index, chlorophyll contents, and fresh weight than those planted alone.

The effect of companion planting on carotenoid contents in lettuce are presented in Figure 6.

Lettuce were planted with chicory and harvested 25 days after sowing (baby leaf stage). Carotenoid contents tended to be higher in lettuce grown with chicory. In particular, lettuce grown with chicory at a 1:3 (lettuce:chicory) ratio had significantly higher $\beta$-carotene $(6.96 \mathrm{mg} / 100 \mathrm{~g}$ FW edible portion) and lutein contents $(6.89 \mathrm{mg} / 100 \mathrm{~g}$ FW edible portion) than lettuce grown alone ( $\beta$-carotene, 3.66 and lutein, $4.0 \mathrm{mg} / 100 \mathrm{~g}$ FW edible portion, respectively). These carotenoid levels were relatively higher than those reported in Lithuania [43] and were within the range of carotenoid levels of various lettuce previously reported in Korea [44]. It should be noted that the carotenoid content of vegetables can vary depending on a number of factors, including the variety [44], harvest time [45], and extraction procedure [46]. On the other hand, chicory intercropped with lettuce at a ratio of 1 to 1 or 1 to 3 had significantly lower lutein and $\beta$-carotene contents than those grown alone as shown in Figure 7.

Lettuce along with chicory represents a fresh leafy vegetable crop with a global production of close to 27 million tons in 2017 [47]. In the cocultivation of lettuce and chicory, the content of $\beta$-carotene in lettuce was $15.8-90.1 \%$, and lutein content was $13.5-72.3 \%$ higher than that of lettuce grown alone. Considering that $\beta$-carotene content of lettuce 
TABLE 3: Plant growth parameters of lettuce (Lactuca savita) and chicory (Cichorium intybus) according to seed mixture ratio in LED plant growth chamber at 25 days after sowing.

\begin{tabular}{|c|c|c|c|c|}
\hline Treatments $^{z}$ & Number of leaves ${ }^{y}$ & Leaf shape index ${ }^{x}$ & Chlorophyll contents (SPAD-value) & Fresh weight $(\mathrm{g})$ \\
\hline \multicolumn{5}{|l|}{ Lettuce } \\
\hline L alone & $7.1 \pm 0.38 \mathrm{a}$ & $4.1 \pm 0.19 \mathrm{a}$ & $17.8 \pm 1.01 \mathrm{bc}$ & $1.50 \pm 0.14 \mathrm{a}$ \\
\hline $\mathrm{L} 1 \mathrm{C} 1$ & $6.7 \pm 0.52 \mathrm{a}$ & $2.2 \pm 0.11 \mathrm{c}$ & $17.1 \pm 1.55 b c$ & $1.32 \pm 0.26 \mathrm{a}$ \\
\hline $\mathrm{L} 1 \mathrm{C} 2$ & $7.9 \pm 0.39 a$ & $2.8 \pm 0.15 b$ & $14.8 \pm 1.03 c$ & $2.08 \pm 0.35 \mathrm{a}$ \\
\hline $\mathrm{L} 1 \mathrm{C} 3$ & $6.5 \pm 0.26 \mathrm{a}$ & $2.5 \pm 0.10 \mathrm{bc}$ & $22.8 \pm 0.61 \mathrm{a}$ & $2.26 \pm 0.56 \mathrm{a}$ \\
\hline $\mathrm{L} 2 \mathrm{C} 1$ & $7.5 \pm 0.33 a$ & $2.4 \pm 0.08 b c$ & $20.2 \pm 1.28 \mathrm{ab}$ & $2.38 \pm 0.21 \mathrm{a}$ \\
\hline $\mathrm{L} 3 \mathrm{C} 1$ & $7.3 \pm 0.37 \mathrm{a}$ & $3.9 \pm 0.25 \mathrm{a}$ & $17.9 \pm 1.00 \mathrm{bc}$ & $1.34 \pm 0.23 \mathrm{a}$ \\
\hline \multicolumn{5}{|l|}{ Chicory } \\
\hline C alone & $5.8 \pm 1.13 \mathrm{a}$ & $3.2 \pm 0.19 b$ & $28.8 \pm 2.97 \mathrm{a}$ & $0.45 \pm 0.17 \mathrm{a}$ \\
\hline $\mathrm{L} 1 \mathrm{C} 1$ & $4.3 \pm 0.47 \mathrm{ab}$ & $2.8 \pm 0.19 b$ & $26.2 \pm 1.04 \mathrm{a}$ & $0.11 \pm 0.02 b$ \\
\hline $\mathrm{L} 1 \mathrm{C} 2$ & $5.5 \pm 0.34 \mathrm{a}$ & $2.5 \pm 0.14 b$ & $25.7 \pm 0.90 \mathrm{a}$ & $0.23 \pm 0.02 \mathrm{a}$ \\
\hline L1C3 & $5.1 \pm 0.41 \mathrm{a}$ & $3.3 \pm 0.19 b$ & $25.1 \pm 1.70 \mathrm{a}$ & $0.20 \pm 0.03 a$ \\
\hline $\mathrm{L} 2 \mathrm{C} 1$ & $4.6 \pm 0.40 \mathrm{a}$ & $2.5 \pm 0.13 b$ & $25.7 \pm 1.00 \mathrm{a}$ & $0.11 \pm 0.02 b$ \\
\hline $\mathrm{L} 3 \mathrm{C} 1$ & $4.7 \pm 0.24 a$ & $4.5 \pm 0.78 \mathrm{a}$ & $21.2 \pm 1.37 \mathrm{~b}$ & $0.14 \pm 0.02 \mathrm{ab}$ \\
\hline
\end{tabular}

Means \pm standard error within column followed by the same letter are not significantly different. L alone, lettuce 40 seeds; C1L1, chicory 20 + lettuce 20; C1L2, chicory 13 + lettuce 27; C1L3, chicory $10+$ lettuce 30; C2L1, chicory $27+$ lettuce 13; C3L1, chicory 30+ lettuce 10; C alone, chicory 40 seeds. Data are means \pm SE, the same letters are not significantly different within the same column according to Duncan's multiple range test at $p<0.05(n=9)$. Leaf shape index is leaf length/leaf width.
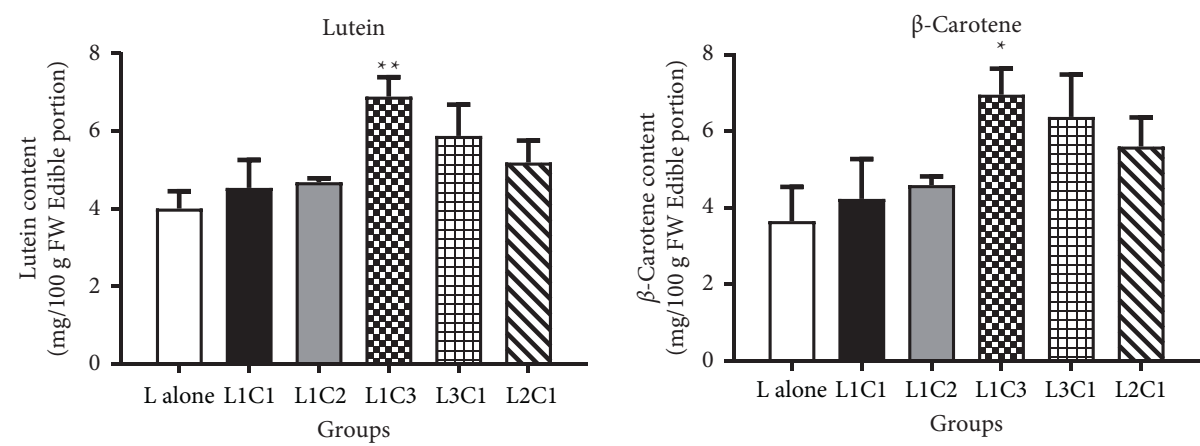

FIGURE 6: Effect of companion planting with chicory on carotenoid contents in lettuce grown in the indoor LED growth chamber for 25 days. Carotenoids were analyzed using an UPLC system (means \pm SE, $n=3$ ).
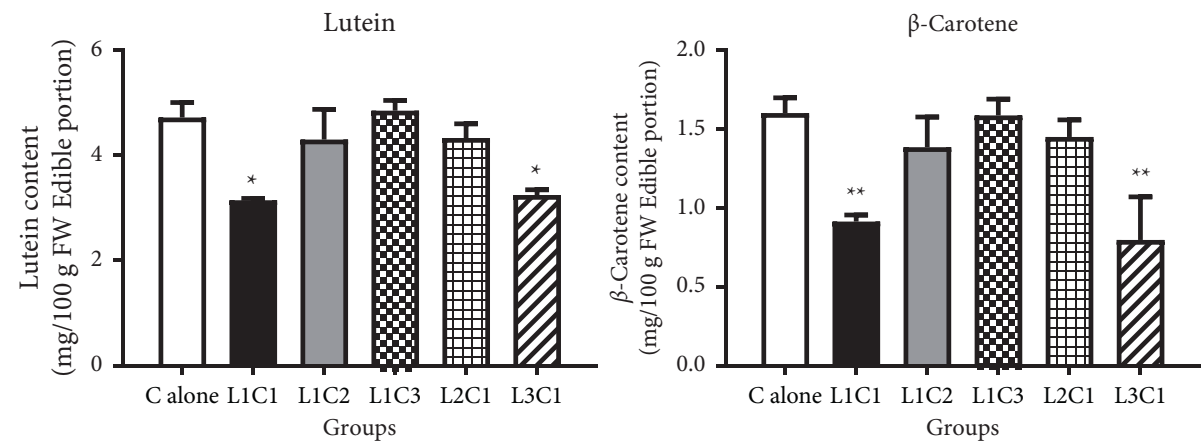

FIGURE 7: Effect of companion planting with lettuce on carotenoid contents in chicory grown in the indoor LED growth chamber for 25 days. Carotenoids were analyzed using an UPLC system (means \pm SE, $n=3$ ).

can be almost doubled from $3.66 \mathrm{mg} / 100 \mathrm{~g}$ to $6.96 \mathrm{mg} / 100 \mathrm{~g}$ of lettuce by companion planting, the $\beta$-carotene intake in one serving of $36 \mathrm{~g}$ lettuce can be increased from $1.32 \mathrm{mg}$ to $2.51 \mathrm{mg}$. It should not be overlooked, however, that the intercropping of lettuce and chicory was not beneficial for chicory in terms of its growth and carotenoid contents.

\section{Conclusions}

This study evaluated the effect of cocultivation of plant foods widely used around the world using an outdoor rooftop garden and indoor LED plant growth chamber. The substantial modification of plant growth, as well as carotenoid contents by cocultivation, shown in this study suggests that 
building-integrated urban agriculture combined with cocultivation may be a good strategy to improve food and nutritional security.

\section{Data Availability}

All the relevant data have been provided in the manuscript. The authors will provide additional details if required.

\section{Conflicts of Interest}

The authors declare no conflicts of interest.

\section{Acknowledgments}

This paper was supported by Konkuk University in 2019.

\section{References}

[1] M. Contesse, B. J. M. van Vliet, and J. Lenhart, "Is urban agriculture urban green space? A comparison of policy arrangements for urban green space and urban agriculture in Santiago de Chile," Land Use Policy, vol. 71, pp. 566-577, 2018.

[2] S. Miccoli, F. Finucci, and R. Murro, "Feeding the cities through urban agriculture the community esteem value," Agriculture and Agricultural Science Procedia, vol. 8, pp. 128-134, 2016.

[3] M. J. Salomon, S. J. Watts-Williams, M. J. McLaughlin, and T. R. Cavagnaro, "Urban soil health: a city-wide survey of chemical and biological properties of urban agriculture soils," Journal of Cleaner Production, vol. 275, Article ID 122900, 2020.

[4] J. Liu, P. Shrestha, L. R. Skabelund, T. Todd, A. Decker, and M. B. Kirkham, "Growth of prairie plants and sedums in different substrates on an experimental green roof in MidContinental USA," The Science of the Total Environment, vol. 697, Article ID 134089, 2019.

[5] Z. Qianqian, M. Liping, W. Huiwei, and W. Long, "Analysis of the effect of green roof substrate amended with biochar on water quality and quantity of rainfall runoff," Environmental Monitoring and Assessment, vol. 191, no. 5, p. 304, 2019.

[6] Y. Zhang, L. Zha, W. Liu, C. Zhou, M. Shao, and Q. Yang, "LED light quality of continuous light before harvest affects growth and AsA metabolism of hydroponic lettuce grown under increasing doses of nitrogen," Plants, vol. 10, no. 1, p. 176, 2021.

[7] G. Pennisi, A. Pistillo, F. Orsini et al., "Optimal light intensity for sustainable water and energy use in indoor cultivation of lettuce and basil under red and blue LEDs," Scientia Horticulturae, vol. 272, no. 15, Article ID 109508, 2020.

[8] C. El-Nakhel, S. A. Petropoulos, A. Pannico et al., "The bioactive profile of lettuce produced in a closed soilless system as configured by combinatorial effects of genotype and macrocation supply composition," Food Chemistry, vol. 309, Article ID 125713, 2020.

[9] F. Zargar Shooshtari, M. K. Souri, M. R. Hasandokht, and S. Kalateh Jari, "Glycine mitigates fertilizer requirements of agricultural crops: case study with cucumber as a high fertilizer demanding crop," Chemical and Biological Technologies in Agriculture, vol. 7, no. 1, pp. 1-10, 2020.

[10] Y. Aghaye Noroozlo, M. K. Souri, and M. Delshad, "Effects of soil application of amino acids, ammonium, and nitrate on nutrient accumulation and growth characteristics of sweet basil," Communications in Soil Science and Plant Analysis, vol. 50, no. 22, pp. 2864-2872, 2019.

[11] A. S. Lithourgidis, C. A. Dordas, C. A. Damalas, and D. N. Vlachostergios, "Annual intercrops: an alternative pathway for sustainable agriculture," Australian Journal of Crop Science, vol. 5, no. 4, pp. 396-410, 2011.

[12] N. Kapoulas, A. Koukounaras, and Z. S. Ilic, "Nutritional quality of lettuce and onion as companion plants from organic and conventional production in north Greece," Scientia Horticulturae, vol. 219, 2017.

[13] T. Matsuoka, K. Tsuchiya, S. Yamada, J. Lundholm, and T. Okuro, "Value of Sedum species as companion plants for nectar-producing plants depends on leaf characteristics of the Sedum," Urban Forestry and Urban Greening, vol. 39, pp. 35-44, 2019.

[14] O. Balmer, C. E. Géneau, E. Belz et al., "Wildflower companion plants increase pest parasitation and yield in cabbage fields: experimental demonstration and call for caution," Biological Control, vol. 76, pp. 19-27, 2014.

[15] A. Elhakeem, W. der Werf, J. Ajal et al., "Cover crop mixtures result in a positive net biodiversity effect irrespective of seeding configuration," Agriculture, Ecosystems \& Environment, vol. 285, Article ID 106627, 2019.

[16] M. K. Souri and M. Bakhtiarizade, "Biostimulation effects of rosemary essential oil on growth and nutrient uptake of tomato seedlings," Scientia Horticulturae, vol. 243, Article ID 472476, 2019.

[17] M. K. Souri and S. Dehnavard, "Tomato plant growth, leaf nutrient concentrations and fruit quality under nitrogen foliar applications," Advances in Horticultural Science, vol. 32, no. 1, pp. 41-47, 2018.

[18] T. Liu, Z. Cheng, H. Meng, I. Ahmad, and H. Zhao, "Growth, yield and quality of spring tomato and physicochemical properties of medium in a tomato/garlic intercropping system under plastic tunnel organic medium cultivation," Scientia Horticulturae, vol. 170, pp. 159-168, 2014.

[19] M. K. Souri and G. Tohidloo, "Effectiveness of different methods of salicylic acid application on growth characteristics of tomato seedlings under salinity," Chemical and Biological Technologies in Agriculture, vol. 6, no. 1, p. 26, 2019.

[20] S. Dehnavard, M. K. Souri, and S. Mardanlu, "Tomato growth responses to foliar application of ammonium sulfate in hydroponic culture," Journal of Plant Nutrition, vol. 40, no. 3, pp. 315-323, 2017.

[21] C. G. Abdel, "Improvement of tomato fruit-set under natural high temperature," The Journal of Duhok University, vol. 9, no. 2, pp. 2-16, 2006.

[22] F. Granado, B. Olmedilla, I. Blanco, and E. Rojas-Hidalgo, "Major fruit and vegetable contributors to the main serum carotenoids in the Spanish diet," European Journal of Clinical Nutrition, vol. 50, no. 4, pp. 246-250, 1996, https://www.ncbi.nlm.nih.gov/entrez/ query.fcgi? $\mathrm{cmd}=$ Retrieve $\& \mathrm{db}=$ PubMed\&dopt $=$ Citation \&list_ uids $=8730612$.

[23] V. Hernández, M. A. Botella, P. Hellín et al., "Phenolic and carotenoid profile of lamb's lettuce and improvement of the bioactive content by preharvest conditions," Foods, vol. 10, no. 1, p. 188, 2021.

[24] F. Ferrón-Carrillo, J. L. Guil-Guerrero, M. J. GonzálezFernández et al., "LED enhances plant performance and both carotenoids and nitrates profiles in lettuce," Plant Foods for Human Nutrition, vol. 76, no. 2, pp. 210-218, 2021.

[25] J. He, N. K. B. Jawahir, and L. Qin, "Quantity of supplementary LED lightings regulates photosynthetic apparatus, 
improves photosynthetic capacity and enhances productivity of cos lettuce grown in a tropical greenhouse," Photosynthesis Research, vol. 149, no. 1-2, pp. 187-199, 2021.

[26] X. Yang, X. P. Wang, Y. B. Qu et al., "Comparing the effects of companion species diversity and the dominant species (Stipa grandis) genotypic diversity on the biomass explained by plant functional trait," Ecological Engineering, vol. 136, pp. 17-22, 2019.

[27] A. Delpino-Rius, J. Eras, A. Marsol-Vall, F. Vilaró, M. Balcells, and R. Canela-Garayoa, "Ultra performance liquid chromatography analysis to study the changes in the carotenoid profile of commercial monovarietal fruit juices," Journal of Chromatography A, vol. 1331, pp. 90-99, 2014.

[28] N. J. A. Conboy, T. McDaniel, A. Ormerod et al., "Companion planting with French marigolds protects tomato plants from glasshouse whiteflies through the emission of airborne limonene," PLoS One, vol. 14, no. 3, Article ID e0213071, 2019.

[29] D. W. Held, P. Gonsiska, and D. A. Potter, "Evaluating companion planting and non-host masking odors for protecting roses from the Japanese beetle (Coleoptera: scarabaeidae)," Journal of Economic Entomology, vol. 96, no. 1, pp. 81-87, 2003.

[30] C. Marty, J.-A. Lévesque, R. L. Bradley, J. Lafond, and M. C. Paré, "Contrasting impacts of two weed species on lowbush blueberry fertilizer nitrogen uptake in a commercial field," PLoS One, vol. 14, no. 4, Article ID e0215253, 2019.

[31] N. Sant'Anna de Medeiros, D. L. Carmo, S. E. Priore, and R. H. S. Santos, "Diverse food in urban gardens in the promotion of food and nutrition security in Brazil: a review," Journal of the Science of Food and Agriculture, vol. 100, no. 4, pp. 1383-1391, 2020.

[32] D. R. Panthee, J. P. Kressin, and A. Piotrowski, "Heritability of flower number and fruit set under heat stress in tomato," HortScience, vol. 53, no. 9, pp. 1294-1299, 2018.

[33] J. Xu, M. Wolters-Arts, C. Mariani, H. Huber, and I. Rieu, "Heat stress affects vegetative and reproductive performance and trait correlations in toamto (Solanum lycopersicum)," Euphytica, vol. 213, no. 7, p. 156, 2017.

[34] R. Fernandez-Cañero, T. Emilsson, C. Fernandez-Barba, and M. Á. Herrera Machuca, "Green roof systems: a study of public attitudes and preferences in southern Spain," Journal of Environmental Management, vol. 128, pp. 106-115, 2013.

[35] I. Tringovska, V. Yankova, D. Markova, and M. Mihov, "Effect of companion plants on toamto greenhouse production," Scientia Horticulturae, vol. 186, pp. 31-37, 2015.

[36] X. Tao, Q. Wu, H. Aalim et al., "Effects of exogenous abscisic acid on bioactive components and antioxidant capacity of postharvest tomato during ripening," Molecules, vol. 25, no. 6, 2020.

[37] M. Naiji and M. K. Souri, "Nutritional value and mineral concentrations of sweet basil under organic compared to chemical fertilization," Acta Sci Pol Hortorum Cultus, vol. 17, no. 2, pp. 165-175, 2018.

[38] T. Grune, G. Lietz, A. Palou et al., "Beta-carotene is an important vitamin A source for humans," Journal of Nutrition, vol. 140, no. 12, pp. 2268S-2285S, 2010.

[39] R. K. Saini, K. R. R. Rengasamy, F. M. Mahomoodally, and Y.-S. Keum, "Protective effects of lycopene in cancer, cardiovascular, and neurodegenerative diseases: an update on epidemiological and mechanistic perspectives," Pharmacological Research, vol. 155, Article ID 104730, 2020.

[40] R. Arunkumar, A. Gorusupudi, and P. S. Bernstein, "The macular carotenoids: a biochemical overview," Biochimica et
Biophysica Acta (BBA) - Molecular and Cell Biology of Lipids, vol. 1865, no. 11, Article ID 158617, 2020.

[41] L. Bedoussac, E.-P. Journet, H. Hauggaard-Nielsen et al., "Ecological principles underlysing the increase of productivity achieved by cereal-grain legume intercropt in organic farming. A review," Agronomy for Sustainable Development, vol. 35, no. 3, pp. 911-935, 2015.

[42] R. A. Dixon and N. L. Paiva, "Stress-induced phenylpropanoid metabolism," The Plant Cell Online, vol. 7, pp. 1085-1097, 1995.

[43] G. Viršile,, J. Miliauskienè, P. J. Haimi, K. Laužikè, A. Brazaitytè, and P. Duchovskis, "The physiological response of lettuce to red and blue light dynamics over different photoperiods," Frontiers of Plant Science, vol. 11, Article ID 610174, 2020.

[44] D.-E. Kim, X. Shang, A. D. Assefa, Y.-S. Keum, and R. K. Saini, "Metabolite profiling of green, green/red, and red lettuce cultivars: variation in health beneficial compounds and antioxidant potential," Food Research International, vol. 105, pp. 361-370, 2018.

[45] A. Elgersma, K. Søegaard, and S. K. Jensen, "Interrelations between herbage yield, alpha-tocopherol, beta-carotene, lutein, protein, and fiber in non-leguminous forbs, forage legumes, and a grass-clover mixture as affected by harvest date," Journal of Agricultural and Food Chemistry, vol. 63, no. 2, pp. 406-414, 2015.

[46] A. Fratianni, R. Mignogna, S. Niro, and G. Panfili, "Determination of lutein from fruit and vegetables through an alkaline hydrolysis extraction method and HPLC analysis," Journal of Food Science, vol. 80, no. 12, pp. C2686-C2691, 2015.

[47] L. Nečemer, N. Ogrinc, D. Žnidarčič, D. Stopar, R. Vidrih, and V. Meglič, "Parameters for discrimination between organic and conventional production: a case study for chicory plants (Cichorium intybus L.)," Food and Chemical Toxicology, vol. 136, Article ID 111109, 2020. 